\section{International Scientific Journal Theoretical \& Applied Science}

p-ISSN: 2308-4944 (print) ｅ-ISSN: 2409-0085 (online)

Year: $2015 \quad$ Issue: $11 \quad$ Volume: 31

Published: $30.11 .2015 \quad$ http://T-Science.org

SECTION 11. Biology. Ecology. Veterinary.
Oksana Yaroslavivna Tverda $\mathrm{PhD}$, senior Lecturer IEE NTUU "KPI”, Ukraine tverdaya@ukr.net

Viktor Danylovych Vorobiov doctor of technical sciences, professor IEE NTUU “KPI”, Ukraine

Yuliia Anatoliivna Davydenko student

IEE NTUU “KPI”, Ukraine

\title{
ESTIMATE THE CONCENTRATION OF DUST DURING EXCAVATION OF THE ROCK MASS AND THE FORMATION OF DUMPS ON PITS
}

Abstract: The process of atmospheric dust at work excavating and building dams. The dependences of the concentration of dust on the height of the step, the height of unloading rock mass, wind speed and direction and seasonal work. Developed schematic map of the maximum values of dust concentration during the formation of the blade on Penyazevichskom career.

Key words: dust concentration, the process of excavation, quarry dump, climatic conditions.

Language: Russian

Citation: Tverda OY, Vorobiov VD, Davydenko YA (2015) ESTIMATE THE CONCENTRATION OF DUST DURING EXCAVATION OF THE ROCK MASS AND THE FORMATION OF DUMPS ON PITS. ISJ Theoretical \& Applied Science 11 (31): 1-7.

Soi: http://s-o-i.org/1.1/TAS-11-31-1 Doi: crossef http://dx.doi.org/10.15863/TAS.2015.11.31.1

\section{ОЦЕНКА КОНЦЕНТРАЦИИ ПЫЛИ ПРИ ЭКСКАВАЦИИ ГОРНОЙ МАССЫ И ФОРМИРОВАНИИ ОТВАЛОВ НА КАРЬЕРАХ}

Аннотация: Рассматривается процесс запыленности атмосферы при работе экскаваторов и формировании отвалов. Установлены зависимости концентрации пыли от высоты уступа, высоты разгрузки горной массы, скорости и направления ветра и сезонности работ. Разработана карта-схема максимальных значений концентрации пьли при формировании отвала на Пенязевичском карьере.

Ключевые слова: концентрация пыли, процесс экскавации, отвал карьера, климатические условия.

\begin{abstract}
Введение
Открытая разработка месторождений полезных ископаемых характеризуется интенсивным загрязнением атмосферы. При выполнении горных работ на карьерах в воздушную среду поступает значительное количество пыли и газов в процессах бурения скважин, взрывной отбойки горной массы, вторичного дробления, экскавации горной массы, разрушения дорожного полотна при движении по нему транспортных средств и отвалообразования [1, c. $1-20 ; 2$, с. 10-15;3].
\end{abstract}

При пылегазовых выбросах преобладают как химические вещества, входящие в состав горных пород, так и вещества, выделяющиеся при работе машин и механизмов от различных технологических процессов. Эмиссия данных вредных веществ приводит к постепенной деградации насаждений, снижение их продуктивности и потери устойчивости. Под влиянием «чужеродных» для живых организмов веществ нарушается ультрамикроскопическая структура клеток растительных организмов, замедляется интенсивность ростовых и продуктивных реакций, снижается продолжительность жизни организмов, ускоряются процессы старения [3; 4, с. 5-7].

Дисперсный состав пыли, образующейся при работе горных машин и механизмов, зависит от технологического процесса, производительности и типа оборудования, физико-механических свойств и минералогического состава разрабатываемых пород, времени года и климатических условий [1, c. $1-20 ; 5 ; 6]$. В современных условиях непрерывная интенсификация добычи минерального сырья на открытых горных работах, обусловленная использованием новой высокопроизводительной техники и технологии, требует совершенствования и разработки новых методов исследования и разработки на их основе способов и средств борьбы с пылью. 
При эксплуатации месторождений полезных ископаемых в конкретных условиях карьеров (разрезов) необходимо проведение исследований по определению объёмов и концентрации пыли для дальнейшего ее подавления и утилизации в местах образования. Это является основой для разработки природоохранных мероприятий на горнодобывающем предприятии. Известные результаты исследований и разработанные на их основе практические рекомендации $[1$, с. $1-20 ; 3$; 7, с. 1-18] в большинстве случаев являются общими и не учитывают конкретные условия разрабатываемых месторождений полезных ископаемых. К ним относятся параметры процессов, координаты рассредоточения отвалов, изменения климатических условий в течении года и др. Поэтому решение этих вопросов для горно-технологических условий конкретного предприятия представляет собой актуальную научно-практическую задачу. отвалов в зависимости от влияющих факторов в условиях Пенязевичского гранитного карьера.

\section{Результаты исследований}

Запылённость рабочей зоны и атмосферы в целом на горнодобывающем предприятии зависит от многих факторов. Среди них преобладающее влияние в загрязнении атмосферы вносят экскаваторные работы и отвалообразования. По результатам обработки статистических экспериментальных данных $[8 ; 9$, c.1-16] установлены зависимости изменения концентрации запылённости воздуха $K\left(\mathrm{Mг} / \mathrm{M}^{3}\right)$ от высоты уступа $H$ (м) и высоты разгрузки ковша экскаватора $h_{p}(\mathrm{M})$.

Приведена зависимость $K=f\left(H_{y}\right)$ для экскаваторов ЭКГ-4 и ЭКГ-8 (рис.1). Из анализа приведённых данных видно, что при работе экскаватора ЭКГ-4 запылённость воздуха больше по сравнению с работой экскаватора ЭКГ-8.

\section{Цель исследования}

Оценка концентрации пыли в процессах экскавации горной массы и формирования

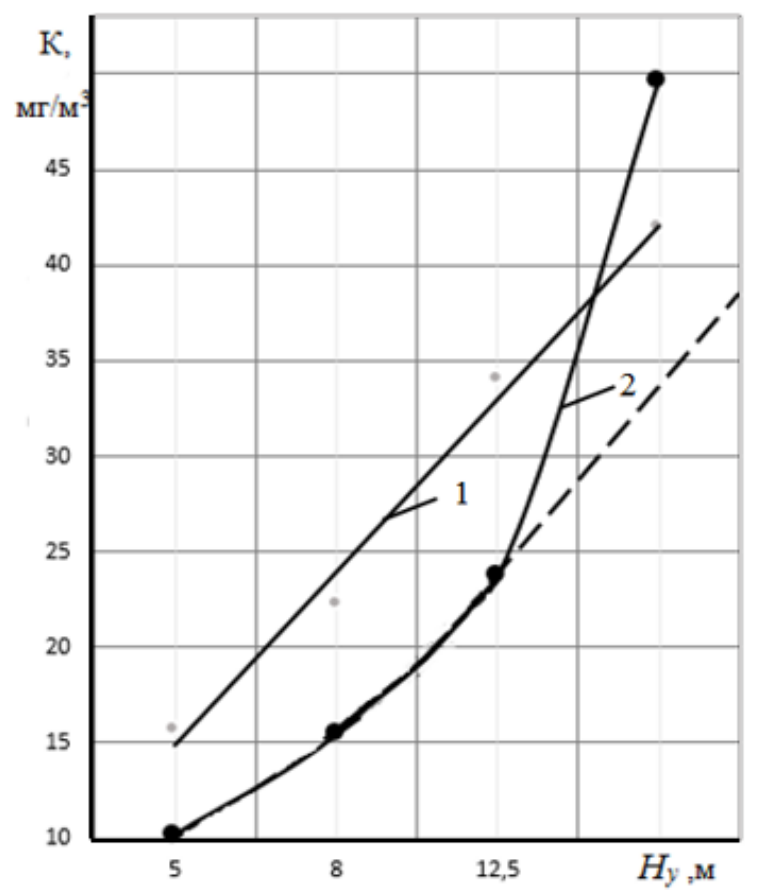

Рисунок 1 - Зависимость концентрации запылённости воздуха в зоне работы экскаваторов ЭКГ - 4 (1) и ЭКГ - 8 (2) при погрузке горной массы от высоты уступа.

С увеличением $H_{y}$ от 5 до 15 м значения $K$ возрастают от 15,7 до $42 \mathrm{мг} / \mathrm{M}^{3}$ для ЭКГ-4 и от

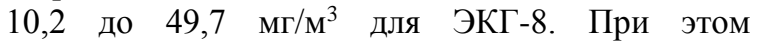
завышенное значение $K$ при $H_{y}=15$ м для ЭКГ-8 объясняется наличием в горной массе большого объёма переизмельченных (мелкодисперсных) фракций, очевидно, по причине недостаточной оптимизации параметров буровзрывных работ.
Характер изменения части кривой (зависимость 2), показан пунктирной линией за счёт логической экстраполяции. В среднем запылённость воздуха при работе экскаватора ЭКГ-4 больше в 1,3 раза по сравнению с экскаватором ЭКГ-8. Зависимости 1 и 2 аппроксимируются соответственно следующими формулами: 


\begin{tabular}{|c|c|c|c|c|c|c|}
\hline Impact Factor: & $\begin{array}{l}\text { ISRA (India) } \\
\text { ISI (Dubai, UAF } \\
\text { GIF (Australia) } \\
\text { JIF }\end{array}$ & $\begin{array}{l}=1.344 \\
=0.829 \\
=0.356 \\
=1.500\end{array}$ & $\begin{array}{l}\text { SIS (USA) } \\
\text { PИHЦ (Russia) } \\
\text { ESJI (KZ) } \\
\text { SJIF (Morocco) }\end{array}$ & $\begin{array}{l}=0.912 \\
=0.179 \\
=1.042 \\
=2.031\end{array}$ & ICV (Poland) & $=6.630$ \\
\hline
\end{tabular}

$$
\begin{gathered}
K=9,06 H_{y}+5,85, \\
K=12,68 H_{y}-6,95 .
\end{gathered}
$$

При разгрузке горной массы из ковша экскаватора, концентрация пыли в воздухе рабочей зоны указанными типами экскаваторов наблюдается прямолинейная зависимость по сравнению с погрузкой горной массы. С увеличением высоты разгрузки ковша $h_{p}$ от 0,5 до 2 м концентрация пыли возрастает. Так для экскаватора ЭКГ-4 значения $K$ увеличиваются от

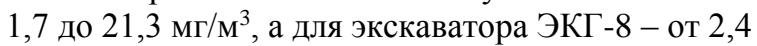
до $31 \mathrm{мг} / \mathrm{M}^{3}$ (рис.2). Концентрация пыли в данном случае для экскаватора ЭКГ-4 (зависимость 1) меньше по сравнению с работой экскаватора ЭКГ-8 (зависимость 2) в среднем в 1,6 раза.

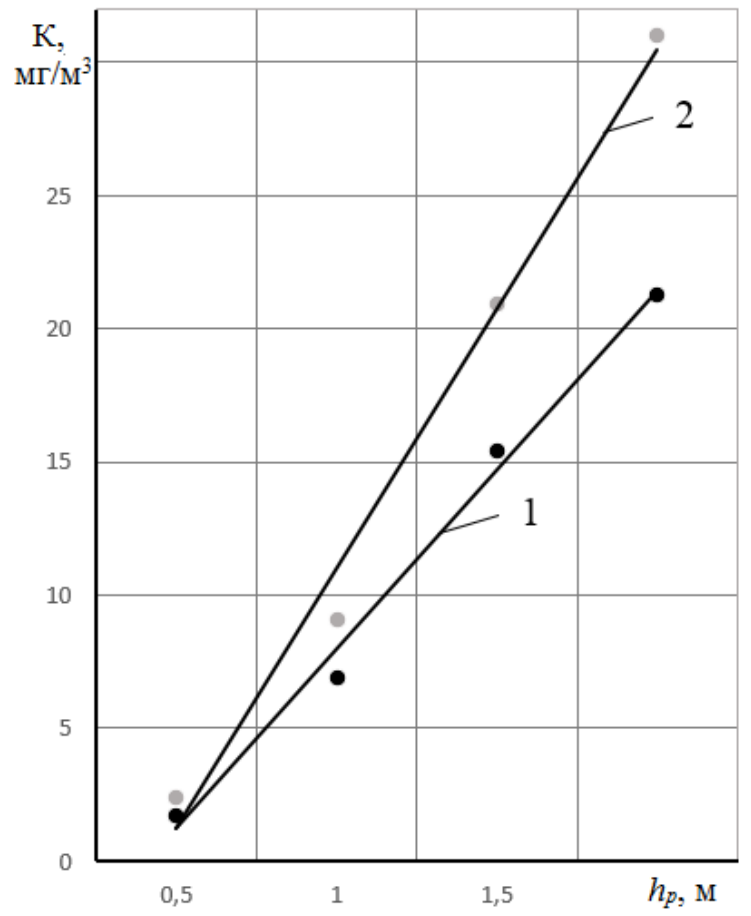

Рисунок 2 - Изменение концентрации пыли в воздухе рабочей зоны в зависимости от высоты разгрузки горной массы ковшом экскаватора: 1 - ЭКГ - 4; 2 - ЭКГ - 8.

Можно констатировать, что запылённость воздуха при экскаваторных работах при черпании горной массы ковшом экскаватора в забое больше в 1,8 раза по сравнению с разгрузкой ковша (по концентрации пыли).

Функциональные зависимости $K=f\left(h_{p}\right)$ для 1 и 2 аппроксимированы соответственно формулами вида:

$$
\begin{gathered}
K=6,73 h_{p}-5,5, \\
K=9,76 h_{p}-8,55 .
\end{gathered}
$$

Концентрация пыли в атмосфере при работе горнотранспортного оборудования зависит от дисперсного состава, климатических условий (влажности, температуры) и скорости ветра [9]. Влияние последнего фактора проверено в условиях отвалообразования на Пенязевичском гранитном карьере.

Пенязевичское месторождение гранитов расположено в Коростенском районе
Житомирской области. В результате его разработки предприятие размещает на своей территории отвал высотой 15 м и шириной 254,6 м. Оценка его влияния на окружающую среду проводилась путем определения концентрации пыли на прилегающей к карьеру территории в зависимости от климатических условий региона с построением карты- схемы рассеивания пыли. Согласно метеорологических данных [10] рассчитана концентрация пыли с отвала карьера в зависимости от изменения скорости ветра и месяца года (табл.1). Расчёты проводились с помощью программы "Gaussian Dispersion Model Calculator". 


\begin{tabular}{|c|c|c|c|c|c|}
\hline Impact Factor: & $\begin{array}{l}\text { ISRA (India) } \\
\text { ISI (Dubai, UAF } \\
\text { GIF (Australia) } \\
\text { JIF }\end{array}$ & $\begin{array}{l}=1.344 \\
=0.829 \\
=0.356 \\
=1.500\end{array}$ & $\begin{array}{l}\text { SIS (USA) } \\
\text { PИНЦ (Russia } \\
\text { ESJI (KZ) } \\
\text { SJIF (Morocco }\end{array}$ & $\begin{array}{l}=0.912 \\
=0.179 \\
=1.042 \\
=2.031\end{array}$ & ICV (Poland) \\
\hline
\end{tabular}

Зависимость концентрации пыли от изменения скорости ветра.

Таблица 1

\begin{tabular}{|c|c|c|}
\hline Месяц & Скорость ветра, $/ \mathbf{c}$ & Концентрация пыли, мг/ $\mathbf{m}^{3}$ \\
\hline 1 & 4,7 & 14,3 \\
\hline 2 & 4,8 & 14,0 \\
\hline 3 & 4,7 & 14,3 \\
\hline 4 & 4,3 & 15,65 \\
\hline 5 & 3,7 & 18,19 \\
\hline 6 & 3,4 & 19,8 \\
\hline 7 & 3,3 & 20,4 \\
\hline 8 & 3,2 & 21,03 \\
\hline 9 & 3,6 & 18,7 \\
\hline 10 & 4,0 & 16,83 \\
\hline 11 & 4,8 & 14,02 \\
\hline 12 & 4,7 & 14,32 \\
\hline
\end{tabular}

Используя полученные данные по концентрации пыли в процессе формирования отвала установлена зависимость $K=f(V)$. Значения $K$ с увеличением $V$ уменьшаются и носят прямолинейный характер изменения (рис.3). Максимальное значение $K\left(21 \mathrm{m \Gamma} / \mathrm{M}^{3}\right)$ получено при $V=3,2 \mathrm{~m} / \mathrm{c}$, а минимальное (14 мг/ $\left.\mathbf{m}^{3}\right)$ - при $V=4,8 \mathrm{~m} / \mathrm{c}$. Таким образом, увеличение скорости ветра в 1,5 раза способствует снижению концентрации пыли в процессе отвалообразования также в 1,5 раза.

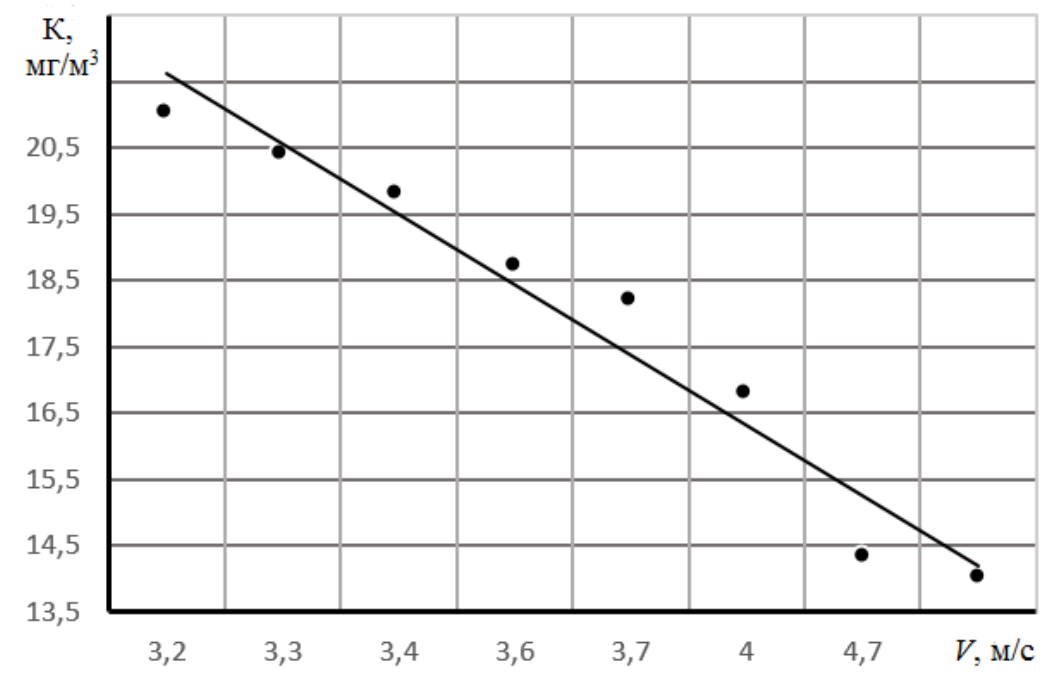

Рисунок 3 - Изменение концентрации пыли в воздухе рабочей зоны в процессе формирования отвала в зависимости от скорости ветра.

Причем, наибольшее значение концентрации пыли приходится на теплое время года, где скорость ветра наименьшая (рис.4). Для расчета рассеивания пыли были приняты данные, приведённые в табл. 2.

На рассеяние пыли в атмосферном воздухе также влияет направление ветра. Для Житомирской области такая повторяемость ветра разных направлений приведена на рис. 5, из которого видно преобладание западного и северо-западного направлений.

Расчёт загрязнения атмосферы выполнен в соответствии с ОНД-86 «Методика расчета концентраций в атмосферном воздухе вредных веществ, содержащихся в выбросах предприятий», с использованием программы УПРЗА «ЭКО центр» [7, с. 1-18; 9, с. 1-16]. 


\begin{tabular}{|c|c|c|c|c|c|c|}
\hline Impact Factor: & $\begin{array}{l}\text { ISRA (India) } \\
\text { ISI (Dubai, UAE } \\
\text { GIF (Australia) } \\
\text { JIF }\end{array}$ & $\begin{array}{l}=1.344 \\
=0.829 \\
=0.356 \\
=1.500\end{array}$ & $\begin{array}{l}\text { SIS (USA) } \\
\text { PИHЦ (Russia) } \\
\text { ESJI (KZ) } \\
\text { SJIF (Morocco) }\end{array}$ & $\begin{array}{l}=0.912 \\
=0.179 \\
=1.042 \\
=2.031\end{array}$ & ICV (Poland) & $=6.630$ \\
\hline
\end{tabular}

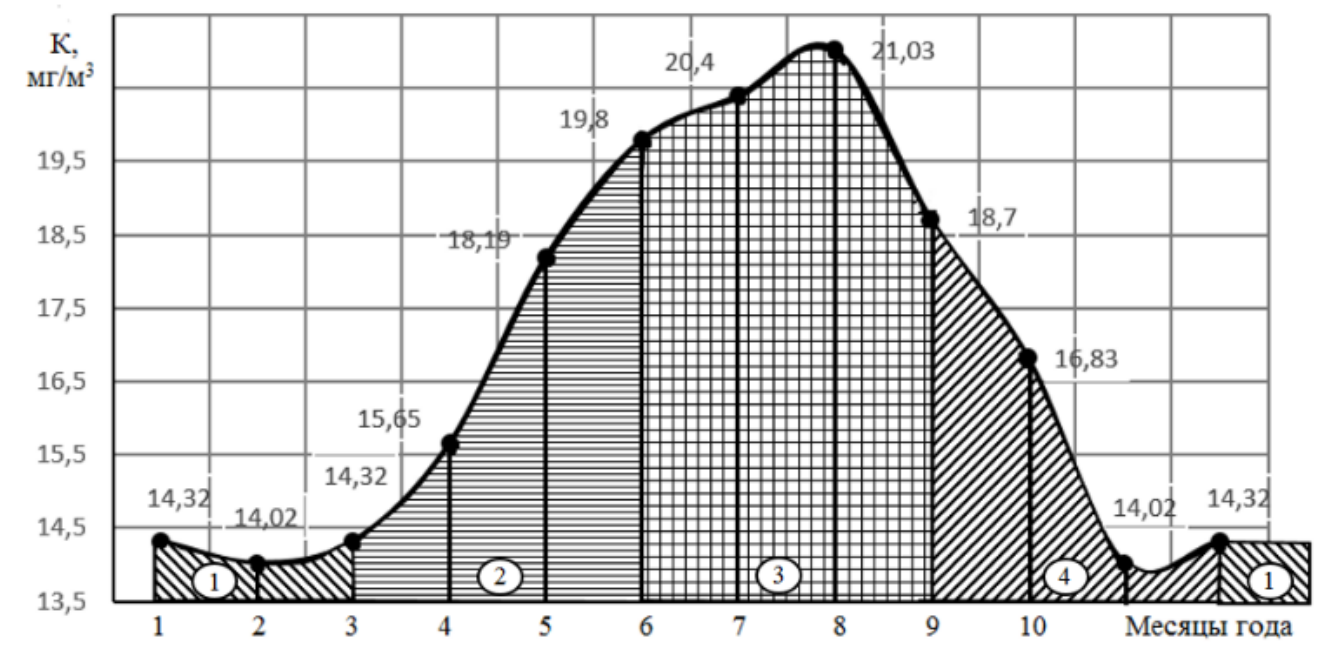

Рисунок 4 - Изменение концентрации пыли в зависимости от времени года: 1 - зима; 2 - весна; 3 - лето; 4 - осень.

Таблица 2

Исходные данные для расчета рассеивания пыли.

\begin{tabular}{|l|c|}
\hline Масса выброса пыли неорганической: $\mathrm{SiO}_{2}(20-70$ \%), г/с & 2,6 \\
\hline Коэффициент осаждения & 3 \\
\hline Коэффициент, зависящий от температурной стратификации атмосферы & 180 \\
\hline Максимальная температура наружного воздуха, ${ }^{\circ} \mathrm{C}$ & 18,0 \\
\hline Минимальная температура наружного воздуха, ${ }^{\circ} \mathrm{C}$ & $-6,0$ \\
\hline Коэффициент рельефа & 1 \\
\hline Скорость ветра, м/с & 3,3 \\
\hline Высота отвала, м & 15 \\
\hline
\end{tabular}

Для источника выброса была определена опасная скорость ветра, максимальная концентрация выброса в долях ПДК и

расстояние, на котором достигается ее максимальное значение (табл.3).

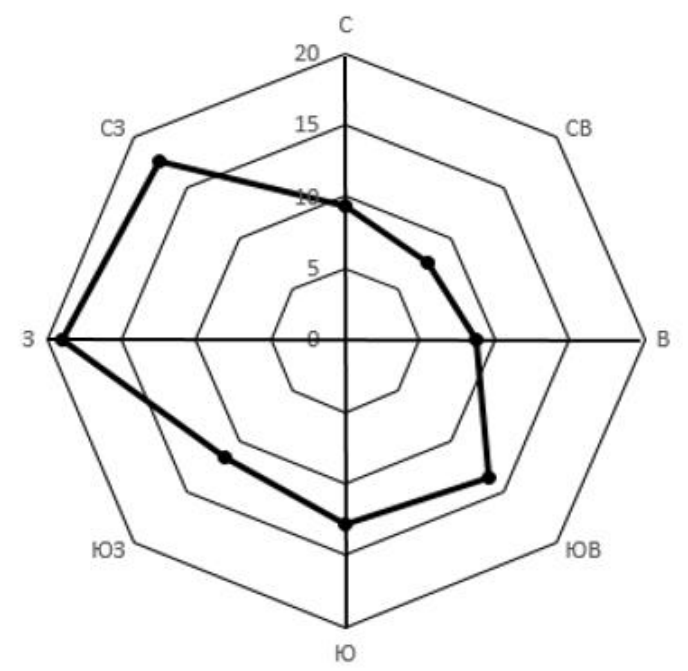

Рисунок 5 - Схема повторяемости направления ветра по румбам (в \%). 


\section{Impact Factor:}

Карта-схема района размещения отвала с нанесенными изолиниями расчетной концентрации, выраженной в долях ПДК, приведена в масштабе 1: 10000 с координатами $\mathrm{X}_{1}, \mathrm{X}_{2}, \mathrm{Y}_{1}, \mathrm{Y}_{2}$ (рис.6).

Параметры источника загрязнения атмосферы.

Таблица 3

\begin{tabular}{|c|c|c|}
\hline \multirow{5}{*}{ Координаты } & $\mathrm{X}_{1}$ & 368,2 \\
\hline & $\mathrm{X}_{2}$ & 1381,8 \\
\hline & $\mathrm{Y}_{1}$ & 1518,2 \\
\hline & $\mathrm{Y}_{2}$ & 1518,2 \\
\hline & ширина, м & 254,6 \\
\hline \multicolumn{2}{|c|}{ Опасная скорость ветра, м/с } & 0,5 \\
\hline \multirow{2}{*}{ Загрязняющее вещество } & код & 2908 \\
\hline & масса выброса, г/с & 2,7 \\
\hline \multicolumn{2}{|c|}{ Максимальная концентрация, д. ПДК } & 7,6 \\
\hline \multicolumn{2}{|c|}{ Расстояние до максимума, м } & 42,75 \\
\hline
\end{tabular}

Анализ расчётов показывает, что концентрация пыли превышает ПДК, которая негативно влияет на состояние здоровья работников карьера и на окружающую среду в целом. Полученные результаты позволяют правильно и точно разработать способы и средства снижения концентрации и локализации пыли. Для этого необходима разработка ряда мероприятий как технологического характера так и организационного с учётом климатических условий региона и сезонности года.

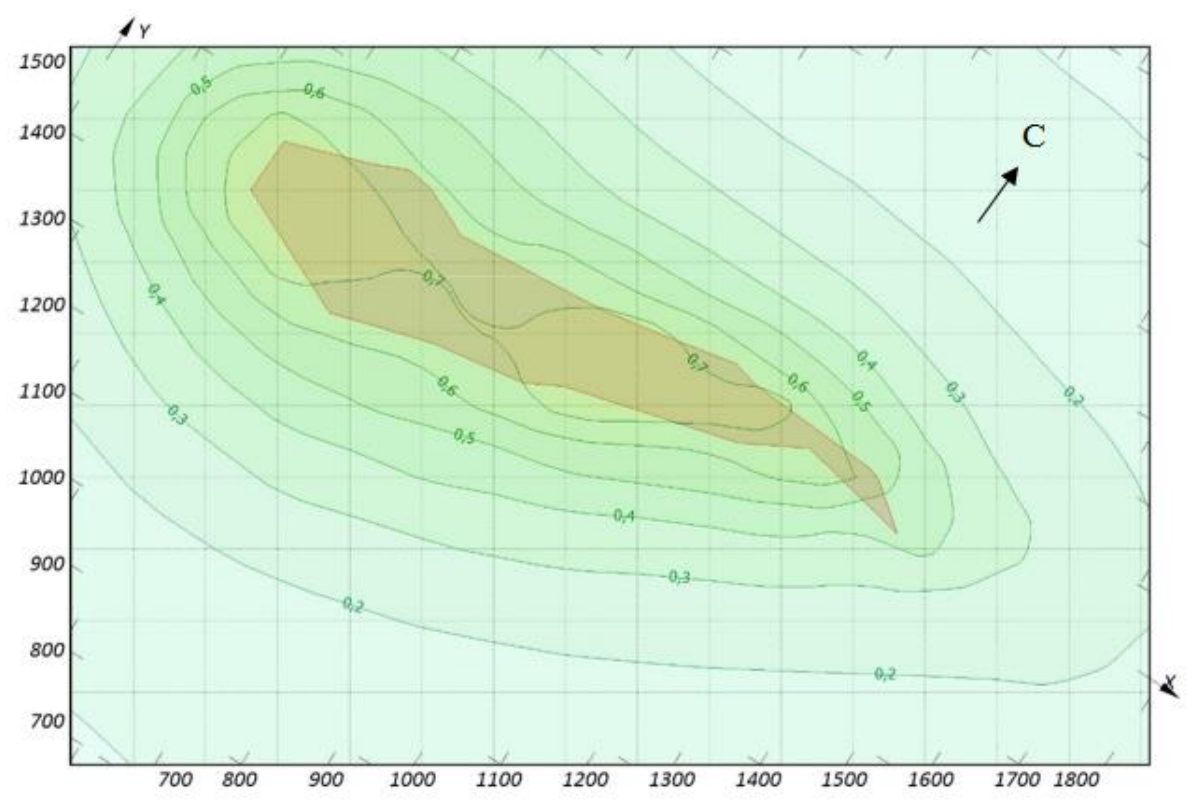

Рисунок 6 - Картограмма изменения концентраций пыли в атмосфере в процессе отвалообразования.

\section{Заключение}

Проведена оценка влияния экскаваторных работ и формирования отвала на концентрацию пыли при разработке Пенязевичского месторождения гранитов на окружающую среду, а также на прилегающую к карьеру зону и территорию Житомирской области в зависимости от климатических условий. Установлена зависимость изменения концентрации пыли при погрузке горной массы экскаватором от высоты уступа и высоты разгрузки ковша в транспортные средства. Разработана карта-схема рассеивания пыли с отвала карьера с учётом скорости ветра и времени года. 


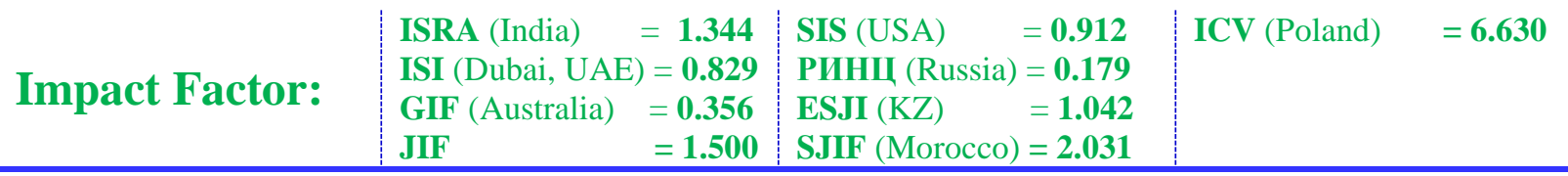

\section{References:}

1. Kuznetsov VS (2006) Otsenka pyilevogo zagryazneniya pri vedenii otkryityih gornyih rabot na osnove ekologicheskogo riska. SanktPeterburg pp. 20.

2. Golik VI (2007) Ohrana okruzhayuschey sredyi: uchebnoe posobie. Moskva: Vyisshaya shkola, 270.

3. Hedler SH, Kuznetsov VS (2015) Prostranstvennoe raspredelenie ekolohycheskoho riska pri rabote zhelezorudnykh karerov. Available: http://cyberleninka.ru/article/n/prostranstvennoe -raspredelenie-ekologicheskogo-riska-prirabote-zhelezorudnyh-karierov (Accessed: 19.09.2015)

4. Slastunov SV, Koroleva VN, Kolikov KS, Kulikova EYu, Vorobev AE, Kachak VV, Babkov-Esterkin VI, Ayruni AT, Batugin AS, Shilov AA (2001) Gornoe delo i okruzhayuschaya sreda. Moskva: Logos, 272.

5. Babets AM, Terentev MV, Cherkaschenko NA (2015) Gornyie raboty i ekologicheskie problemy $\mathrm{v}$ regione KMA. Available: http://cyberleninka.ru/article/n/gornye-raboty-i- ekologicheskie-problemy-v-regione-kma-1

(Accessed: 19.09.2015)

6. Shuvalov YuV, Mohamad A, Bulbashev AP (2015) Atmosfernyie vyibrosyi vrednyih veschestv pri otkryitoy dobyiche poleznyih iskopaemyih.

Available:

http://cyberleninka.ru/article/n/atmosfernyevybrosy-vrednyh-veschestv-pri-otkrytoydobyche-poleznyh-iskopaemyh (Accessed: 19.09.2015)

7. Bakhariev VS (2006) Ekolohichna bezpeka rehionu $\mathrm{v}$ umovakh tekhnohennoho pylovoho zabrudnennia atmosfernoho povitria. Lviv, pp. 18.

8. Loboda AI (1989) Borba s pylyu na otkrytykh hornykh rabotakh. Kyiv: Tekhnika, 152.

9. Kopach PY (1986) Razrabotka sposobov formirovaniya tekhnohennykh otvalnykh massivov, obespechivayushchikh tselenapravlennoe izmenenie ikh svoistv. Dnipropetrovsk pp. 16.

10. Vishnevskii VI (2015) Klimat Zhytomira. Available:

http://www.meteoprog.ua/ru/climate/Zhytomyr. html (Accessed: 19.09.2015) 